\title{
Qualitative Analysis of Student Physical Therapist Reflective Writing: Does an Interprofessional Discharge Planning Simulation Increase their Understanding of the Role they play In Discharge Planning?
}

Leslie M. Smith

University of Michigan Flint, Ilacy@umich.edu

Benjamin Sachs

University of Michigan Flint, bsachs@umich.edu

Karen Berg

University of Michigan Flint, karberg@umich.edu

Megan Keiser

University of Michigan Flint, keiserm@umich.edu

Laura J. Smith

University of Michigan Flint, johlaur@umich.edu

See next page for additional authors

Follow this and additional works at:https://nsuworks.nova.edu/ijahsp

Part of the Education Commons, and the Physical Therapy Commons

\section{Recommended Citation}

Smith LM, Sachs B, Berg K, Keiser M, Smith LJ, Turkelson C, et al. Qualitative Analysis of Student Physical Therapist Reflective Writing: Does an Interprofessional Discharge Planning Simulation Increase their Understanding of the Role they play In Discharge Planning?. The Internet Journal of Allied Health Sciences and Practice. 2020 Jan 01;18(4), Article 12.

This Manuscript is brought to you for free and open access by the College of Health Care Sciences at NSUWorks. It has been accepted for inclusion in Internet Journal of Allied Health Sciences and Practice by an authorized editor of NSUWorks. For more information, please contact nsuworks@nova.edu. 


\title{
Qualitative Analysis of Student Physical Therapist Reflective Writing: Does an Interprofessional Discharge Planning Simulation Increase their Understanding of the Role they play In Discharge Planning?
}

\begin{abstract}
Purpose: The Core Competencies for Entry-Level Practice in Acute Care Physical Therapy provides an expectation of entry-level practice in acute care for physical therapists including discharge planning (DP). Physical therapists (PT), despite having appropriate clinical reasoning and unique skills for determining the functional abilities of patients, are less often a part of the DP process. The purpose of this study was to determine, by use of qualitative analysis of reflective writing, if an interprofessional discharge planning simulation will increase students' understanding of the role of physical therapy in DP. Methods: Students from physical therapy $(n=57)$, undergraduate nursing $(n=36)$, graduate nurse practitioners $(n=2)$, and social work $(n=37)$ participated in a simulation enhanced interprofessional education (Sim-IPE) DP meeting utilizing simulated participants. DPT students were required to complete a reflection paper on this activity. Reflection papers were reviewed and analyzed to identify trends and main themes regarding the role of physical therapist in the discharge planning process. In addition, and sub-themes were then identified through secondary analysis. Results: Three main themes and seven sub-themes were established based on the direct responses to the reflective questions. The first main theme was that it is imperative to identify the main discharge issue particularly as it relates to patient safety and fall risk and to resolve this issue through the DP process. The second main theme was understanding the roles and responsibilities of an interprofessional DP team. The third theme was the identification of the gaps in knowledge with a lack of understanding of the DP process and insurance regulations. Conclusions: DPT students' gained better understanding of the PT's role on the healthcare team as it relates to DP; however, there was a belief that other professions were unaware of the PT's role. The use of a Sim-IPE DP meeting may improve knowledge regarding the discharge process and the role of the PT.
\end{abstract}

\section{Author Bio(s)}

- Leslie M. Smith is an Clinical Associate Professor at the University of Michigan-Flint (UMF). She graduated from the UMF with a Master's Degree in Physical Therapy in 1995 and earned a transition DPT from Utica College in 2015. Leslie was named to the Interprofessional Leadership Fellowship at the University of Michigan in 2016 and completed in 2017.

- Benjamin Sachs is a physical therapist in clinical practice he graduated from the University of Michigan-Flint in 2017. Ben received his BS in Health Science from the University of Central Florida. He served as a Graduate Research Student Assistant for Interprofessional Education.

- Karen Berg is a Clinical Assistant Professor and Co-Associate Director of Clinical Education at the University of Michigan-Flint (UMF). Dr. Berg earned her BS in Physical Therapy from Wayne State University in 1989 and her Transitional DPT from Des Moines University in 2010. She is a Board Certified Orthopedic Clinical Specialist and an APTA Advanced Credentialed Clinical Instructor.

- Megan Keiser is an Associate Professor in the School of Nursing at the University of Michigan-Flint. She received her BSN in 1986 and a Master of Science in Medical-Surgical Nursing in 1990, both from the University of Michigan, Ann Arbor. She received her 
Doctorate of Nursing Practice in 2012 from Wayne State University. She was a member of the inaugural cohort for the International Nursing Association for Clinical Simulation and Learning Simulation Fellowship. She has participated in many grant-funded research projects involving interprofessional practice in health care.

- Laura J. Smith is Associate Professor at the University of Michigan-Flint (UMF). Dr. Smith has extensive teaching experience in entry-level and post-professional physical therapy education. Dr. Smith received her Doctorate in Physical Therapy at University of St. Augustine and PhD from Walden University.

- Carman Turkelson is an Associate Professor of Nursing and the associate director of the nursing simulation center. Dr. Turkelson earned her Doctor of Nursing Practice with a focus on interprofessional education using simulation from the University of Michigan Ann Arbor in 2013. She received her Master of Science in Nursing Education (MSN-Ed) from Michigan State University in 2008. Dr. Turkelson was named to the Interprofessional Leadership Fellowship at the University of Michigan in 2017.

- Amy M. Yorke is an Associate Professor at the University of Michigan-Flint (UMF). Dr. Yorke received a Master's Degree in Physical Therapy in 1993 from UMF and earned her PhD in Interdisciplinary Health Sciences from Western Michigan University in 2013. Dr. Yorke was named as an Interprofessional Leadership Fellow at the University of Michigan in 2017.

\section{Acknowledgements}

The authors would like to acknowledge Margaret Murray-Wright, MSN, RN; Kasie White, LMSW; Alan Hackett, LMSW; and Laura Macias, LMSW, CSW-G for their contributions in the planning stages and facilitation during the event; the University of Michigan-Flint School of Health Professions and Studies and Thompson Center Learning and Teaching for financial support; and physical therapy colleagues preconference simulation course at the APTA Combined Section Meeting 2016 for planning contributions.

\section{Authors}

Leslie M. Smith, Benjamin Sachs, Karen Berg, Megan Keiser, Laura J. Smith, Carman Turkelson, and Amy Yorke 


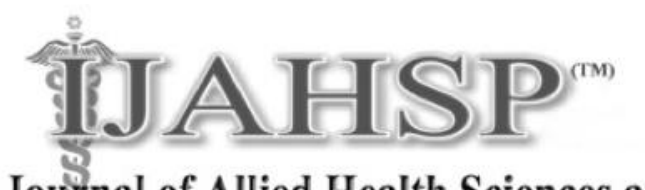

\title{
The Internet Journal of Allied Health Sciences and Practice \\ Dedicated to allied health professional practice and education
}

Vol. 18 No. 4 ISSN 1540-580X

\section{Qualitative Analysis of Student Physical Therapist Reflective Writing: Does an Interprofessional Discharge Planning Simulation Increase their Understanding of the Role they play in Discharge Planning?}

\author{
Leslie M. Smith \\ Benjamin Sachs \\ Karen Berg \\ Megan Keiser, \\ Laura J. Smith \\ Carman Turkelson \\ Amy Yorke \\ University of Michigan Flint \\ United States
}

\begin{abstract}
Purpose: The Core Competencies for Entry-Level Practice in Acute Care Physical Therapy provides an expectation of entry-level practice in acute care for physical therapists including discharge planning (DP). Physical therapists (PT), despite having appropriate clinical reasoning and unique skills for determining the functional abilities of patients, are less often a part of the DP process. The purpose of this study was to determine, by use of qualitative analysis of reflective writing, if an interprofessional discharge planning simulation will increase students' understanding of the role of physical therapy in DP. Methods: Students from physical therapy $(n=57)$, undergraduate nursing $(n=36)$, graduate nurse practitioners $(n=2)$, and social work $(n=37)$ participated in a simulation enhanced interprofessional education (SimIPE) DP meeting utilizing simulated participants. DPT students were required to complete a reflection paper on this activity. Reflection papers were reviewed and analyzed to identify trends and main themes regarding the role of physical therapist in the discharge planning process. In addition, and sub-themes were then identified through secondary analysis. Results: Three main themes and seven sub-themes were established based on the direct responses to the reflective questions. The first main theme was that it is imperative to identify the main discharge issue particularly as it relates to patient safety and fall risk and to resolve this issue through the DP process. The second main theme was understanding the roles and responsibilities of an interprofessional DP team. The third theme was the identification of the gaps in knowledge with a lack of understanding of the DP process and insurance regulations. Conclusions: DPT students' gained better understanding of the PT's role on the healthcare team as it relates to DP; however, there was a belief that other professions were unaware of the PT's role. The use of a Sim-IPE DP meeting may improve knowledge regarding the discharge process and the role of the PT.
\end{abstract}

Key Words. Discharge Planning, Physical Therapy, Interprofessional Education, Simulation 


\section{INTRODUCTION}

The Academy of Acute Care Physical Therapy developed and published the Core Competencies for Entry-Level Practice in Acute Care Physical Therapy which provides an expectation of entry-level practice in acute care for physical therapists. ${ }^{1}$ This document states that the entry-level acute care physical therapist "must be able to make clinical decisions surrounding a safe discharge plan and communicate these decisions with all members of the interprofessional medical team."2( p15) This expectation includes determining the appropriate discharge destination and level of support needed for patient safety in post-acute settings, need for equipment, risk factors for rehospitalization, and the understanding of the regulations imposed by the healthcare systems and payers.2(p15) The purpose of this study was to determine, by use of qualitative analysis of reflective writing, if an interprofessional discharge planning simulation will increase students' understanding of the role of physical therapy in the discharge planning process.

\section{REVIEW OF THE LITERATURE}

Development of a discharge plan, and including the patient and family in the decision making process prior to discharge from an acute care setting, is mandated by the Centers for Medicare \& Medicaid Services.3,4 The goal of discharge planning is to determine an appropriate discharge destination and decide if any follow-up services will be required for continued recovery. ${ }^{5}$

Physical therapists, despite having appropriate clinical reasoning and unique skills for determining the functional abilities of the patients, are less often part of the planning process. ${ }^{6} \mathrm{~A}$ previous report suggests that there is strong support for physical therapists to be a member of the discharge planning team. ${ }^{7}$ Kadivar et al retrospectively looked at the physical therapist participation in interdisciplinary discharge rounds and patient readmission rates, where they found that there were significantly higher readmission rates for patients that were discharged to home when the physical therapist was not part of the interprofessional team. ${ }^{5}$

A requirement exists to expand interprofessional education (IPE) to expose students of other disciplines to the role of physical therapists in the acute treatment of older hospitalized adults. ${ }^{6}$ Interprofessional educational experiences would allow an opportunity for physical therapy students to educate other health professionals about the role of a physical therapist. In addition, expansion of other healthcare professionals understanding of the physical therapist's knowledge regarding discharge recommendations, planning, as well as patient and family education is needed. 6 The integration of IPE into health professions curricula offers a way to increase collaboration among health professionals. Interprofessional education occurs when individuals from two or more professions learn about, from, and with a different profession for a more effective collaboration and to improve individual and population health outcomes. ${ }^{8}$ The Interprofessional Education Collaborative (IPEC) developed four core competencies of interprofessional collaborative practice which includes values/ethics for interprofessional practice; roles and responsibilities; interprofessional communication; and teams and teamwork. ${ }^{9}$ In order to appropriately examine and address patient discharge needs, health care professional students need to have knowledge of their own role with discharge planning as well as the roles and responsibilities of the other professionals caring for a patient. ${ }^{9}$

A previous research study of occupational therapists, physical therapists, and physician assistants students explored the IPE discharge planning process. ${ }^{10}$ This study utilized a discharge planning simulation and small group discussions with students from these programs, to address the complexities of a patient case..$^{10}$ The authors used a survey tool to determine if students had improved understanding of the intricacies of discharge planning, roles of the other professions, and their role on the team for a discharge planning. ${ }^{10}$ The authors concluded that the students enjoyed the activity, had improved role clarification, recognized enhanced clinical reasoning skills, and reported an overall appreciation for the complexities of discharge planning. ${ }^{10}$

\section{METHODS \\ Subjects}

Students from four different professions participated in a discharge planning Sim-IPE. The professions included students from Doctor of Physical Therapy (DPT); Bachelor of Science in Nursing (BSN), Doctor of Nursing Practice (DNP), and Bachelor of Social Work (BSW). The DPT students were in their third and final year of an entry-level physical therapy program. All professions were from the same university in the Midwestern US. Participation in this Sim-IPE was a course requirement for the DPT students and BSN students enrolled in their respective program's medical surgical class. Participation was voluntary for the BSW and DNP students and not directly linked to a specific course in their program. The protocol was granted exempt status by the Institutional Review Board (\#HUM00121119). Prior to the SimIPE, consent for participation was obtained from all students. Only DPT student reflections were used for this study.

\section{Process}

The Sim-IPE discharge planning (DP) experience was designed and developed using the International Nursing Association for Clinical Simulation and Learning (INACSL) Standards of Best Practice: Simulation SM for Sim-IPE. ${ }^{11}$ Training of simulated participants was completed using the Association of Standardized Patient Educators (ASPE) Standards of Best Practice (SOBP). ${ }^{12}$ 
Communication and information regarding the Sim-IPE DP was provided to the students utilizing a web-based learning platform (Blackboard $\left.{ }^{\mathrm{TM}}\right)$. Information on this platform included learning objectives, simulation schedule, general information on discharge planning including an example video of a discharge planning meeting, and the simulated patient's medical record. The electronic medical record included patient demographic information, documentation of emergency room assessment, nursing assessments, current and home medications, labs from the date of admission and the current day, an initial evaluation from the physical therapist and occupational therapist from the previous day, and case management notes (See Appendix A for complete chart). Students were instructed to review the chart prior to attending the discharge planning meeting and knew they would be responsible for representing their profession in the meeting. Criterion Four of the INACSL Standards of Best Practice ("Include an appropriate evaluation plan."11(pS35) suggests that Simulation ${ }^{\mathrm{SM}}$ SimIPE requires that the patient case is developed as a realistic and valid scenario that supports the students learning objectives and expected outcomes. ${ }^{11}$ The patient chart was developed and reviewed by four physical therapy faculty, three nursing faculty, and three social work faculty to ensure the case would meet the student learning objectives and would contain realism, accuracy, and content validity. Student learning objectives for the Sim-IPE DP event were related to discharge planning and the IPEC competencies for collaborative practice and communications as well as the Core Competencies for Entry-Level Practice in Acute Care Physical Therapy.

According to ASPE-SOBP guidelines, a simulated participant needs to work in a safe environment, be given the case-related materials, and have appropriate training to ensure standardization. ${ }^{12}$ One week prior to Sim-IPE DP, the simulated participant training occurred and included these elements. The simulated participants were recruited from area senior centers to enhance the realism of the case because the case involved an 86-year-old male and a younger sibling. Ten total simulated participants were used for the simulation, five playing the role of the patient and five playing the role of the sibling.

During this one-day event, thirty-five discharge planning Sim-IPE sessions were conducted in five separate rooms. In each session, there were one or two DPT students, one or two BSN students, one BSW students, and either a DNP student or a DNP faculty member playing the DNP role. There were one or two faculty facilitators for each room. Prior to the Sim-IPE discharge planning meeting with the patient and his sister, the students had a ten-minute pre-briefing meeting to discuss the case and complete a worksheet to help guide them in the meeting. A total of ten facilitators were used with two in each of the five simulations rooms. The facilitators were faculty members from nursing, social work, and physical therapy departments. The facilitators gave the instructions for the pre-briefing. Following the pre-briefing, the patient and his sister entered the room and the students had twenty minutes for the patient and family interaction. The facilitator(s) sat back silently during the patient simulated meeting. Following the simulated meeting, the simulated participants left the room and each of the facilitators led a thirty minute debriefing.

Each of the Sim-IPE DP sessions were recorded and placed on the e-learning platform for students to review and allow for self-reflection. Only the DPT students were required to complete a reflection paper, using guiding questions to reflect upon. Reflective writing method was chosen to allow the students to examine their understanding of the discharge planning process and allow the researchers to better understand what the students got out of the experience. Support exists in the literature regarding the use of reflective writing as qualitative data. Usher and colleagues suggest that reflective writing by research participants in the form of critical incident analysis is appropriate for use as primary data. ${ }^{13}$ Jasper asserts that reflective writings, subsequently analyzed and interpreted by researchers, are an acceptable source of data in qualitative or mixed methods research. ${ }^{14}$ Wilson-Medhurst recommends that reflective writing assignments be clearly explained to students and that they be used as a means of formative assessment. ${ }^{15}$ Further, reflective writing assignments must be structured and based upon guiding questions. This allows analysis and interpretation of reflective writing as qualitative data because all participants are answering the same prompts or questions thus allowing themes to be identified. ${ }^{15}$ Ash and Clayton state that reflective writing "generates learning, deepens learning, and documents learning."16(p27) There is also support that reflective writing helps to develop clinical reasoning skills as well as enhances higher level conceptual skills by helping the students develop understanding. ${ }^{17,18}$

The two guiding questions that all DPT students were required to answer were 1) What was the discharge issue addressed during this simulation?, and 2) Did you gain further understanding of the role of the physical therapist as a member of the interprofessional team? In addition, the DPT students were asked to answer at least one of the following three questions: 3a) Describe a member(s) of the team who made a strong impression on you, positive or negative; $3 \mathrm{~b}$ ) Discuss any disappointments or successes of the discharge planning meeting you participated in; and 3c) What sorts of things made you feel comfortable and/or uncomfortable when you were working in the interprofessional team? Question 3 was intended to be open ended to allow an expanded view of their overall experience with the SimIPE. The reflective papers were submitted to the e-learning platform within seven days of the Sim-IPE. The primary instructor of the course graded the reflective papers and students were assigned a grade. After grading, the reflective papers were de-identified and coding was performed by two independent researchers. 


\section{RESULTS}

The learners from this Sim-IPE were students from physical therapy ( $n=57)$; nursing $(n=36)$, nursing practitioners $(n=2)$, and social work $(n=37)$. All ( $n=57)$ DPT students completed a reflection paper with guided questions. Qualitative data analysis of the reflective papers were performed by two independent researchers, and they arrived at consensus as to the main themes and sub-themes that emerged. All themes were reviewed and validated by the seven-member research team. All fifty-seven students answered the required first two guiding questions. For questions $3 a, 3 b$, and $3 c$, five students answered all three parts, eighteen students answered two parts, and thirty-three students answered just one part. One student did not answer question 3 at all. In total, $34 / 57$ (59.6\%) students answered question 3a; $31 / 57(54.4 \%)$ answered question $3 b$; and 19/57 (33.3\%) students answered 3c.

For question 1, the analysis was in determining if the students were able to reflectively identify the main discharge issue. Most (94.7\%; $\mathrm{n}=54$ ) of the students correctly identified the primary discharge issue addressed during this simulation. For question $2,75.4 \%(n=43)$ of DPT students reported gaining better understanding of the PT's role on the interprofessional team.

Three main themes were established based on the responses of greater than $50 \%$ of the students. The seven sub-themes were also established based on the responses to the questions by greater than $10 \%$ of the students. Please see Table 1 for a summary of these themes. Once themes were established, selected responses were identified to provide support to the themes.

Table 1. Themes and Sub-Themes Identified in the Student Reflection Papers

\begin{tabular}{|c|c|c|}
\hline Main Themes & Sub-Themes & $\begin{array}{c}\text { Example of a Student Reflection for the Sub- } \\
\text { Theme }\end{array}$ \\
\hline \multirow[t]{3}{*}{$\begin{array}{l}\# 1 \\
\text { It is imperative to identify the } \\
\text { main discharge issue particularly } \\
\text { as it relates to patient safety and } \\
\text { fall risk and to resolve this issue } \\
\text { through the discharge planning } \\
\text { process. }\end{array}$} & $\begin{array}{l}\text { 1a. Discharge destination is not always } \\
\text { straightforward as ambiguity may exist } \\
\text { between the healthcare team, patient, and } \\
\text { family. }\end{array}$ & $\begin{array}{l}\text { "The issue was complicated by the fact that the } \\
\text { patient was very adamant about going home, } \\
\text { although he was not yet able to live } \\
\text { independently. The patient's wishes and persona } \\
\text { expectations did not match the discharge planning } \\
\text { team's assessment. This led to a negotiation } \\
\text { between the discharging planning team and the } \\
\text { patient in order to find a solution everyone was } \\
\text { happy with." }\end{array}$ \\
\hline & $\begin{array}{l}\text { 1b. Team communication is important when } \\
\text { dealing with the discharge issue. }\end{array}$ & $\begin{array}{l}\text { "To address this issue, it required communication } \\
\text { within the different disciplines of the IPE team as } \\
\text { well as communication with the patient and his } \\
\text { sister." }\end{array}$ \\
\hline & $\begin{array}{l}\text { 1c. Lack of team member preparedness negatively } \\
\text { impacted the ability of the team to prioritized } \\
\text { discharge issue }\end{array}$ & $\begin{array}{l}\text { "I was very disappointed with the [team member] } \\
\text { in our group. She didn't read the patient case or } \\
\text { prepare for the discharge meeting. I also felt they } \\
\text { struggled informing the patient what they can do } \\
\text { for them." }\end{array}$ \\
\hline \multirow{3}{*}{$\begin{array}{l}\text { \#2 } \\
\text { Roles and responsibilities of an } \\
\text { interprofessional discharge } \\
\text { planning team }\end{array}$} & $\begin{array}{l}\text { 2a. Understanding of all providers' roles on the } \\
\text { interprofessional team is essential. }\end{array}$ & $\begin{array}{l}\text { "I also gained a better understanding on how } \\
\text { social workers play a big part in the discharge } \\
\text { planning." }\end{array}$ \\
\hline & $\begin{array}{l}\text { 2b. DPT students developed an understanding of } \\
\text { PT's role on the interprofessional team. }\end{array}$ & $\begin{array}{l}\text { "We play a vital role in giving our professional } \\
\text { opinion on where the patient's safety status lies } \\
\text { and what types of services the patient needs in } \\
\text { order to get better and be independent. }\end{array}$ \\
\hline & $\begin{array}{l}\text { 2c. There is a need for PT providers to educate } \\
\text { other members of the interprofessional team } \\
\text { regarding their role. }\end{array}$ & $\begin{array}{l}\text { "I've realized that part of my job will always be } \\
\text { educating other professionals on what PTs } \\
\text { actually do." }\end{array}$ \\
\hline $\begin{array}{l}\# 3 \\
\text { Gaps in knowledge with a lack of } \\
\text { understanding of the discharge } \\
\text { process }\end{array}$ & $\begin{array}{l}\text { 3a. Lack of understanding of insurance regulations } \\
\text { and coverage issues }\end{array}$ & $\begin{array}{l}\text { "We did not know how much his insurance would } \\
\text { cover or if he could afford paying out-of-pocket for } \\
\text { these necessary services." }\end{array}$ \\
\hline
\end{tabular}




\section{Main Theme 1: Identify Main Discharge Issue Related to Patient Safety/Fall Risk}

The first main theme that emerged was that it is imperative for the team to identify the main discharge issue particularly as it relates to the patient's safety and fall risk and how to resolve this issue through the discharge planning process. Examples of how the students reflected on this main theme are as follows:

"This patient had cognition issues as a result of his UTI, decreased strength and aerobic capacity, and impaired balance. This made the patient a severe fall risk and would not be safe being independent at this time until his cognition returned to normal and he regained some strength and balance."

"The issue that was addressed during this simulation was an elderly patient and our safety concerns about him going home."

"From a therapy perspective, the patient returning home independently was out of the question due to patient safety."

Several sub-themes also emerged and were associated with this main theme of identifying the discharge issues. The first sub-theme (1a) was the understanding that the discharge destination was not straightforward due to the patient's desire to return home and the inability to qualify for a skilled nursing facility (SNF) stay. Examples are as follows:

"It was not appropriate to send him home especially since he lived alone and was experiencing an altered mental state. However, the patient was unable to tolerate the 3 hours of daily therapy required with IRF [inpatient rehabilitation facility], did not qualify for SNF, and Medicaid would likely not pay for the 24-hour care needed if he returned home."

"The issue was complicated by the fact that the patient was very adamant about going home, although he was not yet able to live independently. The patient's wishes and personal expectations did not match the discharge planning team's assessment. This led to a negotiation between the discharging planning team and the patient in order to find a solution everyone was happy with."

The second sub-theme (1b) identified that team communication during the Sim-IPE discharge planning meeting was important in identifying the discharge issue. Several students reflected on the team communication in a positive way.

"To address this issue, it required communication within the different disciplines of the IPE team as well as communication with the patient and his sister."

"Having effective communication amongst the healthcare team is important to giving patients the best care that they need."

"I think a level of respect for the other disciplines was evident during the process, which fostered effective communication, and efficient decision making that was ultimately patient centered."

In addition, some students reflected on how poor communication can impact the process and cause frustration.

"The communication between the three of us and the social work student was inadequate. We should have been more thorough in our discussion prior to the patient and the family member entering the meeting. It was frustrating because I did not agree with some of the decisions being made, but also did not feel like I was given a whole lot of opportunity to share my suggestions."

A third sub-theme (1c) that emerged was that the students recognized that team preparedness was essential in identifying and resolving issues related to discharge planning. Discipline was redacted in these two quotes to preserve the collegial relationship.

"I was very disappointed with the [team member] in our group. She didn't read the patient case or prepare for the discharge meeting. I also felt they struggled informing the patient what they can do for them."

"Both [team members] came unprepared for the meeting and did not constructively contribute to the pre-meeting planning. When PT [team member] briefed the group on our findings and we concluded the patient was not safe to return home by himself, one [team member] replied, 'Does he want to go home? If he wants to go home we are sending him home. Why is this even a discussion?' That was very worrisome to me because she either did not listen to our concerns or did not understand that our jobs are to work on getting the patient somewhere safe and using what resources we have to do that." 


\section{Main Theme 2: Roles and Responsibilities}

The second main theme that emerged during analysis of the student reflections was related to roles and responsibilities of the discharge planning team members.

"Throughout the process of discussing which options would be considered and which would be meet the needs and concerns for all parties, my eyes were opened to the roles of social workers and nurses in the discharge planning process. I was thankful for the social worker's input on community resources and insurance issues. On the same note, I was grateful the nurse was available to voice concerns regarding lab values, medications, and hemodynamic stability."

"Overall, I believe this experience has given me an insight to the important role I play as a physical therapist in determining appropriate discharge destinations. It has also increased my knowledge on the roles the other members of the interprofessional team have during this process. Exposure to this scenario will improve my communication skills and problem-solving skills during my clinical rotations."

"Understanding a professional's role in the discharge planning process is essential for successful clinical collaboration."

Three sub-themes associated with this main theme of roles and responsibilities were identified. In the first sub-theme (2a), the DPT students gained increased understanding of other professional roles on the interprofessional team. Some students reflected that this Sim-IPE DP did increase their knowledge the social worker's role. Examples of this are

"I was able to better understand the role of a social worker in patient care and discharge planning because I have never directly worked with one."

"I also gained a better understanding on how social workers play a big part in the discharge planning."

"That being said, I think that working alongside social work helped me to gain a much better understanding of the role they play as a member of the team and how beneficial they can be in this decision making process. I was unaware of the services they could offer prior to this simulation."

In the second sub-theme (2b) related to the roles and responsibilities of the interprofessional team, DPT students believed that they were able to gain a better understanding of the PT's role on the interprofessional team. Many students stated that this Sim-IPE was their first experience in a discharge planning meeting, thus contributing to their better understanding of the PT's role. While other students stated they have had experience in discharge planning meetings, either during a clinical rotation or personal experiences, students still reported gaining a further understanding of their role from taking part in the discharge planning Sim-IPE.

"I believe that I gained further understanding of the role of the physical therapist as a member of the interprofessional team. During the simulation it appeared as though each of the health care professions had a different factor that they were focused on. As physical therapists, I believe that our role is to advocate for the patient's safety. It is our job to evaluate the patient's mobility, functional skills, $A D L$ 's, and their overall safety."

"The sim experience has deepened my understanding of the role of the PT as a member of the interprofessional team... I learned that my role is to stress the need for further PT if applicable and to stress safety while keeping the patient's needs and wants in mind. I also have to understand the views and thoughts of the other health professionals and work with them and the patient to come to the final decision. I learned that this is more of a team effort."

"We play a vital role in giving our professional opinion on where the patient's safety status lies and what types of services the patient needs in order to get better and be independent. It is our duty to relay our medical decision to the rest of the healthcare team so that we can all collaborate on where the patient should be discharged to."

The third sub-theme (2c) emerged as the DPT students reported feeling that students from other health professions were unaware of the physical therapist's role on the discharge planning interprofessional team. An illustration of this is

"I've realized that part of my job will always be educating other professionals on what PTs actually do."

"I also was a little bit annoyed because, as is a constant theme, nobody really seemed to understand the PT role. 
"After this simulation, I learned that very little is understood about physical therapy and their role in healthcare. The social work students did not really grasp our role or what we were trying to convey in regards to sending the patient home."

\section{Main Theme 3: Gaps of Knowledge About Insurance Regulations and Coverage Issues}

Another compelling theme in the reflective writing was that there are a variety of gaps in knowledge that the students were able to identify through participating in this Sim-IPE DP experience. The main theme identified was a lack of knowledge of the discharge process by themselves or by the other members of the team.

"I learned that the physical therapists can add valuable information about the patient's mobility, strength, and aerobic capacity. However, I still don't fully understand the patient discharge process after this simulation."

The primary sub-theme (3a) related to knowledge gaps were regarding payer concerns including insurance regulations and coverage issues.

"There are clearly things that we need to work on, such as a better understanding of power of attorney and some of the insurance information...."

"We did not know how much his insurance would cover or if he could afford paying out-of-pocket for these necessary services."

"One thing that made me uncomfortable was trying to figure out the big picture of all the different costs. The patient kept saying he doesn't have much money so he was not interested in paying out of pocket for additional services. This was difficult to address because we knew the circumstances that our physical therapy services would be covered by his insurance. However, the big picture of all the different services that he would need if he was discharged home may not have been covered by his insurance. It was a challenge to add up all the costs of what the total of everything we were suggesting to explain that total to the patient."

"I think we made it overwhelming for [the patient] and did not have the adequate financial information to allow him or his sister to make an informed decision. To improve we should first off have all the necessary information prepared to demonstrate knowledge of the patient and his case."

\section{DISCUSSION}

In the Core Competencies for Entry-Level Practice in Acute Care Physical Therapy, an entry-level clinician must be able to assess patient safety as it relates to discharge. ${ }^{2}$ In this study, an overarching theme that emerged through analysis of reflective writing was that the DPT students were able to identify the primary issue of patient safety and fall risk. Physical therapists have a role in identifying and managing functional decline before, during, and after an acute hospitalization. ${ }^{6}$ In a retrospective study, Smith et al found that the discharge recommendations made by physical therapist were followed $83 \%$ of the time. ${ }^{7}$ Physical therapists offer a unique perspective as to the functional abilities and how it relates to safety within the home environment. Training future clinicians regarding their role in making these clinical decisions can be challenging in the academic setting; however, simulation can provide the complex realism needed to facilitate learning this necessary content. The discharge planning process is essentially best accomplished by an interprofessional team, and all health care professionals involved in this process need the knowledge, skills and behaviors required for this process.3, 5, 6, 10

The IPEC competency roles and responsibilities has a sub-competency of "Recognize one's limitations in skills, knowledge, and abilities."9(p12) In this study, the DPT students gained a better understanding of the PT's role on the interprofessional team. This suggests that a Sim-IPE may improve this sub-competency as it relates to discharge planning. Another sub-competency in the IPEC roles and responsibilities domain is "Communicate one's roles and responsibilities clearly to patients, families, community members, and other professionals."9(p12) Through analysis of the reflective writing in our study, a sub-theme emerged indicating that other professional students were unaware of the PT's role. This may be explained by a lack of exposure in their programs to the role of a physical therapist and it is important that students learn the responsibility they have in educating other professionals and patients on the role of the PT.

In a previous study, when the discharge recommendations made by a PT were not implemented, patients were nearly three times more likely to be re-admitted. ${ }^{7}$ Individual beliefs about another health care professional's role can affect interprofessional collaboration. ${ }^{19}$ Hence, it is important that other health professionals understand the roles and responsibilities of the PT and include the PT in the patient discharge planning process. Participation in Sim-IPE can improve the knowledge of the roles and responsibilities of the other represented professionals. 10, 20, 21

The discharge process is complex, and students need to recognize communication with all members of the interprofessional team, including the patient and family, is essential in resolving any ambiguity related to discharge needs and discharge disposition. The IPEC Interprofessional Communication Sub-competencies include "Communicate information with patients, families, community members, and 
health team members in a form that is understandable, avoiding discipline-specific terminology when possible" and "Use respectful language appropriate for a given difficult situation, crucial conversation, or conflict." ${ }^{\text {"(p13) }}$ The findings from this study suggest that that team communication was important when dealing with the discharge issue. This is consistent with Smith et al who found that in-person communication between health care providers beyond documentation can increase the awareness of the physical therapist discharge recommendations. ${ }^{7}$

Student preparation for a Sim-IPE includes a review of the content and materials provided prior to the simulation experience. ${ }^{23}$ Being unprepared for a discharge planning meeting can impact the decisions that are being made and cause ineffective collaboration. The DPT students supported this idea throughout several reflections when discussing their frustrations with other team members for not being prepared and how this impacted their ability to contribute to the discussions. In the IPEC team and teamwork competency, a subcompetency requires that the team needs to "Integrate the knowledge and experience of health and other professions to inform health and care decisions..."9(p17) If students come to a Sim-IPE unprepared, they may be unable to fully deliver their knowledge in the discharge planning process.

In this study, one of the knowledge gaps identified in analysis of the reflective papers was a lack of understanding of insurance regulation and coverage for services. In the Core Competencies, an entry-level physical therapist should understand regulations imposed by the healthcare systems and payers. ${ }^{2}$ Lack of knowledge regarding regulatory issues led to some frustration with students and this Sim-IPE unfortunately was unable to fill this gap. On the web-based learning platform, students were provided with a list of potential community resources that would be available for this patient; however, no information regarding coverage or cost of these services was provided. In response to this recognized gap and the gap of knowledge for understanding the discharge process, this Sim-IPE is now being offered an additional time in the DPT curriculum to allow the students an opportunity to have more practice with this important core competency. In addition, social work faculty are now providing additional resources regarding insurance regulation and coverage for services for all the students to review prior to the Sim-IPE DP and during the pre-briefing meeting.

\section{Limitations}

The main limitations in this study were that only DPT students' reflections were required which limits generalizability to other professions. In addition, results from this study are based on a controlled simulated activity and may not translate to clinical settings. This study was conducted in a single institution and was a one-time activity which further limits the results being generalized. Future studies should intentionally request reflections from the other professions to determine if the role of the PT in the discharge process is better understood following the discharge planning Sim-IPE, and examine clinical behaviors regarding DPT students' ability to make safe and appropriate discharge recommendations for patients in the acute care setting. It would also be beneficial to explore this Sim-IPE activity over time by exploring the impact on clinical education experiences and future clinical practice. In addition, using this Sim-IPE in multiple institutions to compare results and improve the generalizability of the study.

\section{CONCLUSION}

Discharge planning knowledge is a core competency required for the entry-level acute care physical therapist and the use of a preprofessional Sim-IPE DP meeting may improve knowledge regarding discharge planning and the role physical therapists play in this process. In the assessment of this Sim-IPE DP meeting, we were able to meet the student learning objectives as well as provide guidance in moving forward.

\section{Acknowledgements}

The authors would like to acknowledge Margaret Murray-Wright, MSN, RN; Kasie White, LMSW; Alan Hackett, LMSW; and Laura Macias, LMSW, CSW-G for their contributions in the planning stages and facilitation during the event; the University of Michigan-Flint College of Health Sciences and Thompson Center Learning and Teaching for financial support; and physical therapy colleagues pre-conference simulation course at the APTA Combined Section Meeting for planning contributions. 


\section{References}

1. Greenwood KC, Stewart E, Hake M, Milton E, Mitchell L, Sanders B. Defining entry-level practice in acute care physical therapist practice. JACPT. 2017; 8(1):3-10.

2. Greenwood KC, Stewart E, Hake M, Milton E, Mitchell L, Sanders B. Core competencies for entry-level practice in acute care physical therapy: First edition 2015. Available at http://c.ymcdn.com/sites/www.acutept.org/resource/resmgr/Core_Competencies_of_Entry-L.pdf

3. Smith LM, Keiser M, Turkelson C, Yorke AM, Sachs B, Berg K. Simulated interprofessional education discharge planning meeting to improve skills necessary for effective interprofessional practice. Prof Case Manag. 2018 Mar/Apr;23(2):75-83. doi: 10.1097/NCM.0000000000000250.

4. CSM. Joint Commission. Transitions of care: The need for a more effective approach to continuing patient care. June 2012.

5. Kadivar Z, English A, Marx B. Understanding the relationship between physical therapist participation in interdisciplinary rounds and hospital readmission rates: Preliminary study. Phys Ther. November 2016;96(11):1705-1713.

6. Falvey J, Burke R, Malone D, Ridgeway K, McManus B, Stevens-Lapsley J. Role of physical therapists in reducing hospital readmissions: Optimizing outcomes for older adult during care transitions from hospital to community. Phys Ther. August 2016;96(8):1125-1134.

7. Smith BA, Fields CJ, Fernandez N. Physical therapists make accurate and appropriate discharge recommendations for patients who are acutely ill. Phys Ther. 2010;90(5):693-703. doi:10.2522/ptj.20090164.

8. World Health Organization (WHO). Framework for action on interprofessional education \& collaborative practice. 2010. Geneva: World Health Organization. See http://whalibdoc.who.int/hq/2010/WHO_HRH_HPN_10.3 eng.pdf.

9. Interprofessional Education Collaborative. Core competencies for interprofessional collaborative practice: 2016 update. 2016. Washington, DC: Interprofessional Education Collaborative.

10. Kraft $\mathrm{S}$, Wise $\mathrm{H}$, Jacques $\mathrm{P}$, Burik J. Discharge planning simulation: Training the interprofessional team for the future workplace. J Allied Health. Fall2013 2013;42(3):175-181.

11. INACSL standards of best practice: SimulationSM simulation-enhanced interprofessional education (Sim-IPE). Clinical Simulation in Nursing. December 2, 2016;12:S34-S38.

12. Lewis KL, Bohnert CA, Gammon WL, Holzer H, et al. The association of standardized patient educators (ASPE) standards of best practice (SOBP). Adv Simul. 2017; 2:10. https://doi.org/10.1186/s41077-017-0043-4

13. Usher K, Francis D, Owens J. Reflective writing: A strategy to foster critical inquiry in undergraduate nursing students. Aust $J$ Adv Nurs. 1999; 17(1); 7-12.

14. Jasper MA. Using reflective writing within research. J Res Nurs. 2005;10(3); 247-260.

15. Wilson-Medhurst S. Supporting student development using reflective writing. Investigations in University Teaching and Learning. 2005, 2(2); 89-93.

16. Ash SL, Clayton PH. Generating, deepening, and documenting learning: The power of critical reflection in applied learning. JALT. 2009; 1;25-48.

17. Callister M. The use of student of student journals in nursing education: Making meaning out of clinical experience. J Nurs Educ. 1990;32(4);185-186.

18. Cise JS, Wilson CS, Thie MJ. A qualitative tool for critical thinking skill development. Nurse Educ. 2004;36(4);147-151.

19. Ebert L, Hoffman K, Levett-Jones T, Gilligan C. 'They have no idea of what we do or what we know': Australian graduates' perceptions of working in a health care team. Nurse Educ Pract. September 2014;14(5):544-550.

20. Zamjahn J, Beyer E, Alig K, Mercante D, Carter K, Gunaldo T. Increasing awareness of the roles, knowledge, and skills of respiratory therapists through an interprofessional education experience. Respir Care. May 2018;63(5):510-518.

21. King J, Beanlands S, Summers I, et al. Using interprofessional simulation to improve collaborative competences for nursing, physiotherapy, and respiratory therapy students. J Interprof Care. September 2016;30(5):599-605.

22. Tyerman J, Luctkar-Flude M, Graham L, Coffey S, Olsen-Lynch E. Pre-simulation preparation and briefing practices for healthcare professionals and students: a systematic review protocol. JBI Database of Systematic Reviews \& Implementation Reports. 2016;14(8):80-89. doi:10.11124/JBISRIR-2016-003055. 
Appendix A Patient's Medical Record

\begin{tabular}{|c|c|c|c|c|}
\hline \multicolumn{5}{|c|}{ Orders } \\
\hline Lab & Date & & & Order \\
\hline Labs Ordered & $11 / 8 / 20160600$ & \multicolumn{3}{|c|}{ CBC, basic metabolic panel } \\
\hline Medications & $11 / 7 / 2016$ & \multicolumn{3}{|c|}{ see MAR; saline lock } \\
\hline Nursing orders & $11 / 7 / 2016$ & \multicolumn{3}{|c|}{$\begin{array}{l}\text { VS, neuro check every } 4 \text { hours; I\&O; oxygen via NC as needed to keep O2 sat } \\
>94 \%\end{array}$} \\
\hline Activity order & $11 / 7 / 20160600$ & \multicolumn{3}{|c|}{ Up with assistance } \\
\hline $\mathrm{PT} / \mathrm{OT} / \mathrm{SLP}$ & $11 / 7 / 20160600$ & \multicolumn{3}{|c|}{ PT/OT evaluate and treat } \\
\hline Nutritional Services & $11 / 7 / 2016$ & \multicolumn{3}{|c|}{ Regular diet } \\
\hline \multicolumn{5}{|c|}{ Healthcare Team Initial and Progress Notes } \\
\hline \multicolumn{2}{|l|}{ Note } & \multicolumn{3}{|c|}{ Information } \\
\hline History & $11 / 7 / 2016$ & \multicolumn{3}{|c|}{$\begin{array}{l}\text { 86-year-old male came to the ED via EMS with altered mental status with } \\
\text { altered sodium labs, UTI, elevated WBC and neutrophils. Patient was found by } \\
\text { a neighbor after not being seen for a couple days. Patient was found sitting in a } \\
\text { recliner chair and was difficult to arouse and showing signs of confusion. } \\
\text { Patient lives alone in his home. Patient was admitted under medical short stay } \\
\text { status. PMH: Hypertension, Type } 2 \text { DM, Osteoarthritis, lumbar stenosis, s/p } \\
\text { total knee replacement } 3 \text { years ago. }\end{array}$} \\
\hline Nursing Note - EC & $11 / 7 / 20160713$ & \multicolumn{3}{|c|}{$\begin{array}{l}\text { First contact with patient - brought in by EMS due to MS change. UA obtained, } \\
\text { results pending. Head CT scan completed - results pending. }\end{array}$} \\
\hline Nursing Note - EC & $11 / 7 / 20160802$ & \multicolumn{3}{|c|}{$\begin{array}{l}\text { Head CT scan without acute finding. UA resulted - positive for UTI. Cipro } \\
400 \mathrm{mg} \text { IVPB hung per order. Also received } 40 \mathrm{mEq} \mathrm{KCl} \text { IVPB per order for } \mathrm{K} \text { of } \\
3.1 \text { on admit labs. Will monitor. }\end{array}$} \\
\hline Nursing Notes & $11 / 7 / 20161011$ & \multicolumn{3}{|c|}{$\begin{array}{l}\text { Nursing Admit Note: Patient admitted to room and unit, no family present. VS } \\
\text { stable. Call light within reach. Admission assessment completed. }\end{array}$} \\
\hline Nursing Notes & $11 / 8 / 20160123$ & \multicolumn{3}{|c|}{$\begin{array}{l}\text { Patient found naked in hallway stating that he was looking for the bathroom. He } \\
\text { had urinated on the floor near his bed. He became agitated and aggressive } \\
\text { when staff attempted to direct his back to his room. MD contacted and order } \\
\text { obtained for Haldol } 2 \mathrm{mg} I V \times 1 \text {. Will monitor patient response to Haldol and } \\
\text { place NA as sitter at bedside. }\end{array}$} \\
\hline Nursing Notes & $11 / 8 / 20160612$ & \multicolumn{3}{|c|}{$\begin{array}{l}\text { Patient slept well after Haldol - sitter at bedside. Currently awake, resting } \\
\text { quietly, asking when he can go home. Social work consult pending for DC } \\
\text { planning. }\end{array}$} \\
\hline Social Work Notes & $11 / 8 / 20160923$ & \multicolumn{3}{|c|}{$\begin{array}{l}\text { Case opened. Patient admitted } 11 / 7 / 2016 \text { as medical short stay. No family } \\
\text { present at bedside and patient is drowsy and confused. MD has cleared patient } \\
\text { for change to PO antibiotics and discharge. No qualifying LOS for discharge to } \\
\text { facility as Medicare is only insurance and requires a } 3 \text { midnight LOS for } \\
\text { ECF/SAR placement. Will attempt to schedule family meeting as patient lives } \\
\text { alone and this is not a safe discharge plan per PT/OT notes. }\end{array}$} \\
\hline Social Work Notes & $11 / 8 / 20161004$ & \multicolumn{3}{|c|}{$\begin{array}{l}\text { Family contacted (sister) by phone and are en route to hospital for family } \\
\text { meeting at } 11 \text { am. Nursing and therapy aware. }\end{array}$} \\
\hline PT Notes & $11 / 7 / 20161615$ & \multicolumn{3}{|c|}{$\begin{array}{l}\text { Patient was seen by physical therapy this date for assessment of balance, gait } \\
\text { and safety. See evaluation }\end{array}$} \\
\hline OT Notes & $11 / 7 / 20160815$ & \multicolumn{3}{|c|}{ Patient was seen by occupational therapy (please see evaluation). } \\
\hline \multicolumn{5}{|c|}{ Medications } \\
\hline Date Initiated & Medications & Dose & Route & Frequency \\
\hline $11 / 7 / 2016$ & Ciprofloxacin & $400 \mathrm{mg}$ & IVPB & q 12 hours \\
\hline $11 / 7 / 2016$ & Metformin & $850 \mathrm{mg}$ & PO & $\mathrm{BID}(9 \mathrm{am}, 5 \mathrm{pm})$ \\
\hline $11 / 7 / 2016$ & Lisinopril & $20 \mathrm{mg}$ & $\mathrm{PO}$ & daily \\
\hline
\end{tabular}




\begin{tabular}{|c|c|c|c|c|c|}
\hline $11 / 7 / 2016$ & Furosemide & $20 \mathrm{mg}$ & $\mathrm{PC}$ & \multicolumn{2}{|l|}{ q 12 hours } \\
\hline $11 / 7 / 2016$ & Ibuprofen & $600 \mathrm{mg}$ & $\mathrm{PC}$ & \multicolumn{2}{|c|}{ q 8 hours PRN joint pain } \\
\hline $11 / 7 / 2016$ & Tylenol & $650 \mathrm{mg}$ & $\mathrm{PC}$ & \multicolumn{2}{|c|}{ q 4 hours PRN fever, HA } \\
\hline \multicolumn{6}{|c|}{ Lab Values } \\
\hline Lab Category & Test & $11 / 7 / 20160730$ & & $11 / 8 / 20160600$ & Reference Value \\
\hline \multirow[t]{10}{*}{ CBC / Coagulation } & $\mathrm{RBC}$ & 4.3 & & 4.4 & $4.2-5.4 \times 106 / \mathrm{mm} 3$ \\
\hline & $\mathrm{HCT}$ & 38.2 & & 38.4 & $40-50 \%$ \\
\hline & $\mathrm{HgB}$ & 12.8 & & 12.9 & $13-16 \mathrm{~g} / \mathrm{dL}$ \\
\hline & WBC & 18.3 & & 16.5 & $4.5-11 \times 109 / \mathrm{L}$ \\
\hline & Platelets & 188,000 & & 192,000 & $\begin{array}{l}150,000-400,000 / \\
\mathrm{mm} 3\end{array}$ \\
\hline & Neutrophils & 18 & & & $2.0-7.0 \times 109 / \mathrm{L}$ \\
\hline & Lymphocytes & 2.8 & & & $1.0-3.0 \times 109 / \mathrm{L}$ \\
\hline & Monocytes & 0.3 & & & $0.2-1.0 \times 109 / \mathrm{L}$ \\
\hline & Eosinophils & 0.7 & & & $0.02-0.5 \times 109 / \mathrm{L}$ \\
\hline & Basophils & 0.1 & & & $0.02-0.1 \times 109 / \mathrm{L}$ \\
\hline Endocrine & Blood Glucose & 178 & & 242 & $70-110 \mathrm{mg} / \mathrm{dL}$ \\
\hline & $\mathrm{A} 1 \mathrm{C}$ & 6.7 & & & $4-5.6 \%$ \\
\hline Electrolytes & $\mathrm{Na}+$ & 149 & & 142 & $135-147 \mathrm{mEq} / \mathrm{L}$ \\
\hline & $\mathrm{Cl}-$ & 100 & & 98 & $95-105 \mathrm{mEq} / \mathrm{L}$ \\
\hline & $\mathrm{K}+$ & 3.1 & & 3.6 & 3.5-4.5 mEq/L \\
\hline Cardiac markers & CK & 8 & & & $0-3 \mathrm{ng} / \mathrm{ml}$ \\
\hline & Troponin & $<0.04$ & & & $<0.4 \mathrm{ng} / \mathrm{ml}$ \\
\hline Kidney function/ Protein & Creatinine & 1.38 & & 1.32 & $0.6-1.2 \mathrm{mg} / \mathrm{dL}$ \\
\hline & BUN & 25 & & 22 & $7-18 \mathrm{mg} / \mathrm{dL}$ \\
\hline & Albumin & 2.8 & & 2.9 & $3.5-5.5 \mathrm{~g} / \mathrm{dL}$ \\
\hline & Uric Acid & 6.1 & & & $3.0-8.2 \mathrm{mg} / \mathrm{dL}$ \\
\hline Urinalysis & Color & Amber & & & Yellow \\
\hline & Clarity & cloudy & & & Clear \\
\hline & Glucose & $1+$ & & & negative \\
\hline & Bilirubin & negative & & & negative \\
\hline & Ketones & $1+$ & & & negative \\
\hline & Specific Gravity & 1.056 & & & $1.005-1.030$ \\
\hline & Blood & $2+$ & & & negative \\
\hline & $\mathrm{pH}$ & 7.5 & & & $5.0-8.0$ \\
\hline & Protein & $1+$ & & & negative \\
\hline & Urobilibubin & 1 & & & $0.2-1.0$ \\
\hline & Nitrate & $1+$ & & & negative \\
\hline & Leuk. estrace & $3+$ & & & negative \\
\hline & $\mathrm{RBC}$ & 21 & & & $0-3$ \\
\hline & WBC & 50 & & & $0-5$ \\
\hline
\end{tabular}




\begin{tabular}{|c|c|c|c|c|c|}
\hline & Epithelial cells & & 57 & & none \\
\hline & Bacteria & & $2+$ & & negative \\
\hline Urine Culture & Gram Stain & man & gram negative bacilli & & negative \\
\hline & & Diag & ostic Tests & & \\
\hline & & & Date & & Result \\
\hline Chest X-Ray AP and & & & $11 / 7 / 2016$ & No aCl & te intrathoracic process \\
\hline Head CT scan withol & & & $11 / 7 / 2016$ & No act & e intracranial pathology \\
\hline & Physic & al Ther & py Initial Evaluation & & \\
\hline History & & & & & \\
\hline $\begin{array}{l}86 \text {-year-old male can } \\
\text { Patient was found by } \\
\text { arouse and showing }\end{array}$ & $\begin{array}{l}\text { ED via EMS with altered } m \\
\text { or after not being seen for } \\
\text { confusion. Patient lives alo }\end{array}$ & $\begin{array}{l}\text { ntal st } \\
\text { coupl } \\
\text { e in his }\end{array}$ & $\begin{array}{l}\text { us with altered sodiur } \\
\text { days. Patient was for } \\
\text { nome. Patient was ac }\end{array}$ & $\begin{array}{l}\text { JTI, eleva } \\
\text { ig in a re } \\
\text { under obs }\end{array}$ & $\begin{array}{l}\text { ed WBC and neutrophils. } \\
\text { liner chair and was difficult to } \\
\text { ervational status. }\end{array}$ \\
\hline PMH: Hypertension, & nitis, lumbar stenosis & & & & \\
\hline PSH: s/p total knee $r$ & ent 3 years ago. & & & & \\
\hline $\begin{array}{l}\text { Patient lives alone in } \\
\text { walker at home but } \mathrm{w} \\
\text { that he has a cat and } \\
\text { minutes away. He al }\end{array}$ & $\begin{array}{l}\text { home with 6-steps to ente } \\
\text { e to recall whether it had w } \\
\text { d about his cat being at ho } \\
\text { sister that checks on him f }\end{array}$ & $\begin{array}{l}\text { a porc } \\
\text { eels or } \\
\text { ee alon } \\
\text { rly reg }\end{array}$ & $\begin{array}{l}\text { and a railing on both } \\
\text { hot or whether he use } \\
\text { Patient states he ha } \\
\text { arly. }\end{array}$ & $\begin{array}{l}\text { it too wid } \\
\text { ch. Patie } \\
\text { and } 1 \text { da }\end{array}$ & $\begin{array}{l}\text { to use both. Patient has a } \\
\text { t denies any falls. Patient states } \\
\text { ighter that both live about } 30\end{array}$ \\
\hline Patient's goals for the & o return home. & & & & \\
\hline Systems Review & & & & & \\
\hline Cardiopulmonary & Integumentary & & Musculoskeletal & & Neuromuscular \\
\hline HR: 76 bpm & $\begin{array}{l}\text { Skin intact with no sores } \\
\text { change, or bruising }\end{array}$ & blor & Height: 5'10" & & Reflexes: $2+$ in bilateral LEs \\
\hline BP: $116 / 62 \mathrm{mmHg}$ & & & Weight: $165 \mathrm{lbs}$. & & $\begin{array}{l}\text { Sensation: intact in bilateral } \\
\text { LEs }\end{array}$ \\
\hline SPO2: $97 \%$ room air & & & $\begin{array}{l}\text { Strength: weakness } \\
\text { UEs }\end{array}$ & LEs and & Balance: impaired \\
\hline RR: 18 breaths/min & & & $\begin{array}{l}\text { Posture: rounded s } \\
\text { sitting. }\end{array}$ & & $\begin{array}{l}\text { Coordination: normal upon } \\
\text { observation }\end{array}$ \\
\hline No edema & & & & & \\
\hline${ }^{*}$ vitals taken in sitting & & & & & \\
\hline Tests and Measures & & & & & \\
\hline Cognition: & & Moto & Function: & & \\
\hline $\begin{array}{l}\text { A\&O } \times 1 \text { (self only). } F \\
\text { incidence leading to }\end{array}$ & $\begin{array}{l}\text { as unable to recall the } \\
\text { ng to the hospital. }\end{array}$ & $\begin{array}{l}\text { MMT } \\
\text { abdu } \\
\text { excep }\end{array}$ & $\begin{array}{l}\text { creen: } 3 / 5 \text { right hip fle } \\
\text { ion/adduction, } 4 / 5 \mathrm{kne} \\
3 / 5 \text { for BIL shoulder } \mathrm{f}\end{array}$ & $\begin{array}{l}5 \text { left hip } \\
\text { sion, } 3 / 5 \\
\text { 5xSTS: N }\end{array}$ & $\begin{array}{l}\text { exion, 3/5 bilateral hip } \\
\text { ankle DF/PF. UE's grossly 4/5 } \\
\text { odified using UEs } 37 \text { seconds }\end{array}$ \\
\hline Pain: & & Func & onal Mobility: & & \\
\hline $\begin{array}{l}\text { Patient reported a } 2 / \\
\text { region that was desc }\end{array}$ & $\begin{array}{l}\text { cated at his lumbar spine } \\
\text { constant dull ache or }\end{array}$ & $\begin{array}{l}\text { Supin } \\
\text { assis }\end{array}$ & $\begin{array}{l}\text { to sit: performed usin } \\
\text { nce }\end{array}$ & lling tech & ique and required moderate \\
\hline & & Sit to & tand: performed with & e assista & \\
\hline Following treatment, & Nas rated as a 4-5/10. & $5 \times \mathrm{ST}$ & Unable & & \\
\hline Sensation: & & Gait: & & & \\
\hline $\begin{array}{l}\text { Light touch: intact in } \\
\text { tested) }\end{array}$ & Es (lower legs and feet & $\begin{array}{l}\text { Patie } \\
\text { walke } \\
\text { flexec }\end{array}$ & $\begin{array}{l}\text { walked for } 10 \text { feet } x \\
\text { and minimal assistan } \\
\text { umbar spine. Gait sp }\end{array}$ & $\begin{array}{l}\mathrm{r} \text { in room } \\
\text { ent walk v } \\
\mathrm{m} / \mathrm{sec}\end{array}$ & $\begin{array}{l}\text { and back to bed with front wheel } \\
\text { ith rounded shoulders and }\end{array}$ \\
\hline Balance: & & Aero & c Capacity Tests: & & \\
\hline
\end{tabular}


Sitting balance: initially required min assist sitting at the edge of bed, but once positioned correctly was able to sit unsupported.

Standing Balance: Able to stand for 30 seconds unsupported but holding the walker; min assist for dynamic gait activities.

\section{Assessment}

Risk assessment/Precautions:

Fall risk due to his advanced age, slow gait speed, decreased quadriceps strength and assistance and AD needed for mobility

\section{Diagnosis/Prognosis:}

PT Diagnosis: Patient has weakness in all 4 extremities, limited aerobic capacity, pain and poor posture. These impairments impact his functional mobility, balance, gait speed, and ability to ambulate in safely alone, get in and out of bed, and climb stairs which can affect his accessibility to his home and public places.

Prognosis: The prognosis is fair. Because the patient has limited family support and is motivated to get back home. However, factors that will affect his prognosis include his increased age, some cognitive and memory deficits, limited functional mobility and a number of stairs required to access his home. It is anticipated that the patient will need continued functional mobility training, balance training, strengthening and endurance exercises. Patient is not safe to live alone at home at this time.

Goals:

1. Patient will transfer supine to sit, and sit to supine with supervision in 2 days.

2. Patient will ambulate safely 25 feet with front wheeled walker and supervision in 2 days.

3. Patient will demonstrate independence with a home exercise program with visual cues only in 2 days.

4. Patient will have improved gait speed to $0.4 \mathrm{~m} / \mathrm{s}$ in 2 days.

5. Patient will transfer sit to stand with use of UEs and supervision in 2 days.

Plan

Intervention provided today:

Evaluation performed along with patient education, bed mobility, transfers (supine to sit, sit to stand, stand to sit, and sit to supine), ambulation/gait training, and LE/UE strengthening exercises.

Intervention plan:

- $\quad$ Continue exercises for LE / UE strengthening, will provide written instructions at next visit

- $\quad$ Gait training with front wheeled walker and addressing gait speed

- Transfers with progressively decreased assistance

- Stair training, may need family training on how to assist

Discharge recommendation:

Patient needs continued 24 hour care, he would not tolerate an IRF at this time and may not qualify for a SNF. If patient were to return home, he would need 24 hours care, family training, wheelchair and possible bedside commode.

\section{Charge for today's visit:}

CPT Codes:

- 97001 Physical Therapy Evaluation: 1 unit

. 97530 Therapeutic Activities (bed mobility/transfer training): 1 unit 